\title{
O ENFERMEIRO E O ENSINO NÃO FORMAL EM SAÚDE: UMA ABORDAGEM TEÓRICA
}

Maria Inês Monteiro Cocco*

\begin{abstract}
RESUMO - A autora faz uma revisão teórica sobre o ensino não formal em saúde, com ênfase na saúde coletiva. É discutido o papel do Enfermeiro enquanto profissional da área de saúde, a sua relação com o cliente e a prática social. São discutidos aspectos da hegemonia do saber profissional/cliente.
\end{abstract}

ABSTRACT - The author does a theoretical revision about non-formal health teaching, with an emphasis on community health. The nurses role is discussed as a health professional her relationship with the client and her social practice. Some aspects of the domination of knowledge of the professional/client are discussed.

\section{INTRODUC̣ÃO}

() reduzido número de pesquisas e trabalhos publicados sobre educação e saúde, atividades educativas realizadas com o cliente, grupos para acompanhamento de patologias crônicas, levou-nos à realização desta revisão teórica sobre o assunto.

Desta reflexão crítica sobre educação e saúde, surgiram algumas indagações: o ensino realizado em saúde coletiva tem um caráter informal, não normal ou é formal? Como se dá a inserção do Enfermeiro nas atividades referentes a educação e saúde? Ao realizar programas/ações educativas com o cliente, a quem estará servindo? Ao Estado, enquanto planejador das açōes gerais? À Instituição, enquanto que mantém a alienação? À si próprio, enquanto profissional de saúde, detentor de um saber hegemônico, que é passado em pequenas parcelas ao cliente, como forma de manter o poder sobre ele?

Foi feita a revisão bibliográfica da Revista Brasileira de Enfermagem no período de 1972 a 1986; da Revista Paulista de Enfermagem no período de 1981 a 1986; de textos atuais do Ministério da Saúde referentes à educação e saúde, e de textos atuais sobre edu(ação popular, buscando subsídios para delinear a atuação do Enfermeiro e/ou Equipe Multiprofissional no trabalho com grupos de clientes e/ou ação educativa. linear a atuação do Enfermeiro e/ou Equipe Multiprofissional no trabalho com grupos de clientes e/ou ação educativa.

\section{REVISÃO BIBLIOGRÁFICA}

CARDOSO DE MELO (1984), apresenta uma visão crítica sobre os discursos predominantes na educação sanitária no Brasii no decorrer deste século. "A educação sanitária que emerge nos anos 20 é parte integrante de uma nova concepção de serviços de saúde - a Saúde Pública. Até 1920, a estrutura sanitária brasileira era "caracterizada pela criação de unidades especializadas para fazer face a problemas específicos" (RAMOS, 1976). "A partir de 20, a estrutura sanitária norte-americana passa a influenciar decisivamente a estrutura sanitária brasileira"... Em 1931, Vargas, através de um decreto, extinguia os Centros de Saúde... A partir de 1942, e principalmente após a II Guerra Mundial, a educação sanitária ressurge, através de inúmeros trabalhos publicados com um novo discurso... Na segunda metade dos anos 50 são introduzidas novas idéias - desenvolvendo a organização comunitária, participação, integração dos setores "atrasados" no de-

\footnotetext{
* Enfermeira. Supervisora Técnica do Serviço de Enfermagem dos Ambulatórios do H.C./UNICAMP - Mestranda em Educação - UNICAMP.
} 
senvolvimento nacional. Esse discurso atravessa os anos 60. A partir de 1967, há uma reformulação geral na educação sanitária, que passa a ser denominada educação em saúde pública ou simplesmente educação em saúde e, com freqüência, educação para a saúde" (CARDOSO DE MELLO, 1984).

A enfermagem, inserida no contexto da época e como parte das profissões da área de saúde, também sofre alterações, como veremos a seguir.

Segundo SCHIMIDT (1984) "a enfermagem moderna surgiu no Brasil, na área de Saúde Pública, face à necessidade episódica de controlar a febre amarela. Quando houve o recrudescimento dessa epidemia, também desapareceu o interesse pela enfermagem... 0 desenvolvimento industrial trouxe profundas alterações na prática da assistência, que passou a ser predominantemente curativa. Com isso os hospitais passaram a necessitar de enfermeiras e as escolas de enfermagem foram readaptando seus currículos para atender à demanda de preparar profissionias para a assistência de enfermagem em hospitais".

" 0 final da década de 50 e toda a década de 60 conheceu-se uma grande expansão da Previdência Social, alicerçada na assistência curativa, assim como uma expansão da rede hospitalar privada, proliferação de escolas médicas e redução do exercício liberal da medicina. ...A of erta de trabalho predominantemente hospitalar, fez o enfermeiro afastar-se do campo de Saúde Pública e das atividades que mais o caracterizavam, quais seja, as ações de educação sanitária, e as "aplicações de medidas destinadas à prevenção de doenças'... O número de profissionais formados era insuficiente para atender a demanda dos hospitais" (SCHMIDT, 1984).

Segundo VIEIRA \& SILVA (1982), "na década de 70 a estrutura social vigente sob a égide do sistema capitalista, continua influenciando sobremaneira as práticas de saúde, realçando a assistência hospitalar. Esta se torna quase hegemõnica como mercado de trabalho para enfermagem o qual, praticamente, define o perfil do enfermeiro".

Com a Conferência de Alma-Ata em 1978, preconizando "saúde para todos no ano 2000", é que, segundo SCHIMIDT (1984), "começaram a surgir maiores oportunidades para trabalho do Enfermeiro em centros de saúde e ambulatórios, onde ele encontra, além de barreiras estruturais rígidas de organização, os costumes e tradições de trabalho desencadeados por apenas uma determinada categoria profissional".

$\mathrm{Na}$ época atual a discussão em torno da saúde concentrou-se em 1986, na 8. CONFERÊNCIA NACIONAL DE SAÚDE (1986) realizada em Brasília, no período de 17 a 21 de março. No relatório final, temos a seguinte conceituação: "em seu sentido mais abrangente, a saúde é a resultante das condições de alimentação, habitação, educação, renda, meio-ambiente, trabalho, transporte, emprego, lazer, liberdade, acesso e posse da terra e acesso a serviços de saúde,... definese no contexto histórico de determinada sociedade e num dado momento de seu desenvolvimento, devendo ser conquistada pela população em suas lutas cotidianas. Direito à saúde significa a garantia pelo Estado, de condições dignas de vida e de acesso universal e igualitário às ações e serviços de promoção, proteção e recuperação de saúde, em todos os seus níveis, a todos os habitantes do território nacional, levando ao desenvolvimento pleno do ser humano em sua individualidade.

Deste conceito amplo de saúde e desta noção de direito como conquista social, emerge a idéia de que o pleno exercício do direito à saúde implica em garantir: - trabalho em condições dignas, com amplo conhecimento e controle dos trabalhadores sobre o processo e o ambiente de trabalho;

- alimentação para todos, segundo as suas necessidades;

- moradia higiênica e digna;

- educação e informação plenas;

- qualidade adequada do meio-ambiente;

- transporte seguro e acessível;

- repouso, lazer e segurança;

- participação da população na organização, gestão e controle dos serviços e ações de saúde;

- direito à liberdade, à livre organização e expressão;

- acesso universal e igualitário aos serviços setoriais em todos os níveis".

Esta redefinição de saúde, colocando-a como parte de um todo na sociedade, é que deveria estar sendo realizada de fato, na prática. $O$ que encontramos comumente, é a sua presença freqüente no discurso, seja do Estado, dos profissionais, das associações; mas no momento em que deveria ser implementada, não dá espaço social para tal. Há pressões dos grupos hegemõnicos, e o grau de conscientização e organização da sociedade, não são relevantes.

De acordo com REZENDE (1984), "as práticas de saúde na ordem capitalista pautam-se pelos valores da produtividade. A saúde, antes de ser vista como um direito, passou a ser desejada como fator necessário a essa produtividade, e a doença o transtorno econõmico. As práticas de saúde capitalistas visam manter e aumentar a força de trabalho".

"Por outro lado, as ações de saúde pública dirigidas, principalmente, à atenção primária e ao controle de enfermidades, canalizadas sobretudo para a parcela da população marginalizada do sistema produtivo, é de controle do Estado. ...O Estado preocupa-se com os aspectos de saúde desta população, e promove programasalternativos na área, como uma necessidade de adequação de sua base produtiva, cuja sobrevivência é fundamental para a manutenção do regime", de acordo com VIEIRA \& SILVA (1982); SILVA (1981).

MINAYO (1986) explica por que a medicina popular costuma ter tanto êxito com as classes populares: 
"mesmo recorrendo à magia para a cura, ela capta os elementos da condição de vida. Nos terreiros e nos centros as pessoas são tratadas como indivíduos diferenciados e únicos, com sua história, preocupações e experiências. ...Por que, na verdade, ela cristaliza uma resistência dos usuários à prática muitas vezes autoritária da medicina e da imposição de valores que resulta dessa prática".

Para REZENDE (1986) "a pressão social é um fator importante que se interpõe entre a percepção dos sintomas e a busca de assistência de saúde. A sociedade estimula pessoas sadias e produtivas. Assumir o papel de doente é sair da engrenagem social, segregar-se, parar de produzir, passar a consumir, exigir cuidados especiais, onerar um orçamento familiar, afastar-se das atividades usuais e distanciar-se da família e dos amigos. Assumir, então, o papel de doente, é renunciar, mesmo que transitoriamente, ao desempenho de seu papel social".

SILVA (1981) apresenta uma abordagem da enfermagem neste contexto: "a necessidade de se buscarem as articulações do fenômeno estudado com a estrutura social mais ampla, o que signigica, no nosso caso, encarar a enfermagem como parte integrante da estrutura social global e não a parte dela, como uma ilha isolada. ...0 que queremos dizer, mais explicitamente, é que cada paciente, em nossa sociedade, tem vinculação de classe. O corpo de um burguês, de um operário não tem o mesmo valor para o sistema político-econômico'.

Para BRANDÃO (1980) "em todas as sociedades é a educação um dos mais efetivos instrumentos de controle social. Os seus conteúdos de ef eito socializador em geral conduzem mensagens que legitimam uma ordem social vigente. Isto significa que, ao ensinar alguma coisa a algumas pessoas, a educação ensina os termos de uma ordem social que deve ser reconhecida como necessária e legítima, na mesma medida em que ensina os conhecimentos e as habilitações necessárias e legítimas para que as pessoas da sociedade preservem e reproduzam com as suas idéias (próprias mas inculcadas pela educação), e com as suas atitudes (apreendidas mas sob a forma de controle exercido pela sociedade através da educação), a ordem econômica, política e ideológica da sociedade".

É esta a nossa preocupação fundamental ao analisar o que está sendo publicado sobre educação e saúde no Brasil: a ordem social acima citada, onde serão reproduzidos modelos sociais, onde o cliente poderá estar sendo manipulado pelo profissional, sem ter consciência disto.

Os inúmeros questionamentos, que não são novos, sobre o perfil do Enfermeiro, o espaço a ser ocupado por ele, a expansão das outras profissões da área da saúde em detrimento da enfermagem, podem ser apreendidos no discurso de CASTRO (1982): "'a permanência de uma profissão no mundo depende de sua ca- pacidade de evoluir e adaptar-se às contingências sociais, no sentido de ter sua utilidade reconhecida por aqueles aos quais se propõe beneficiar. ...A intenção do Enfermeiro... é a de proporcionar cuidados que interessam à saúde, em todos os seus aspectos. Um tão abrangente propósito lhe garante pelo menos em tese presença obrigatória nos cenários de prestação de serviços de saúde. Mas também se constitui em obstáculo, porque empresta à profissão uma natureza essencialmente interdisciplinar. Esta característica tem confundido a muitos de nós e também às pessoas junto às quais trabalhamos. Em outro nível, isto tem dificultado e até mesmo impedido que a enfermagem seja reconhecida como área específica do conhecimento humano, isto é, como ciência".

Segundo RIBEIRO (1982) "na área da saúde e da educação o compromisso social dos profissionais, num primeiro nível de responsabilidade assume características muito particulares, pois, o relacionamento entre indivíduos e profissionais, por força da natureza do trabalho que deve realizar, tem que ser direto.

A caracterização da/o enfermeira/o como administradora/or dos serviços de enfermagem, e a serviço das instituições, tem servido para que a elas/eles sejam negadas maiores oportunidades do trabalho educativo, seja de pessoal, seja de pacientes ou clientes dos serviços ou dos indivíduos da comunidade. Essa imagem também influencia autoridades de saúde, os quais demonstram, claramente, em suas definições políticas ou normativas, que não conhecem o potencial dos profissionais de enfermagem" (RIBEIRO, 1982).

Segundo REZENDE (1986), "qualquer prática que se desenvolve, no bojo de uma dada sociedade, é necessariamente constituída pelo conjunto de suas relações sociais e comprometida com determinada maneira de perceber essa mesma sociedade e de inserir-se nela. Em toda prática social existe, portanto, a impossibilidade de isenção ideológica. A Enfermagem não pode ser reduzida a um certo número de procedimentos técnicos, absolutamente objetivos e alheios ao contexto social. Ela é e sempre será, uma prática política, e como tal, profundamente carregada de valores. A técnica não é uma categoria em si mesma, mas sim um instrumento atributivo de uma cultura. Ao se apregoar a competência técnica do enfermeiro, dicotomizada da inserção política, está se escamoteando a mais fecunda questão que deve ser colocada - a que ideologia serve essa competência técnica?

O que temos visto na prática são enfermeiros com formação voltada exclusivamente para a área administrativa, e o círculo vicioso que a prática deve ser mudada, porém os alunos atuam e tomam-na como modelo.

De acordo com BUENO (1986) “...espera-se que o currículo das escolas de enfermagem, deva estar sempre vinculado ao momento histórico e inserido na rea- 
lidade concreta na qual se desenvolve a prática profissional'

ALMEIDA (1985) mostra que "o outro pressuposto importante é que o ensino formal é uma instituição que não tem força total para transformar a prática; está distante dela e parece correr paralelo à ela e são poucos os momentos de imbricação destas duas práticas, a do ensino e a da prática propriamente dita.

GRAMSCI, citado por BLASS (1980), destaca o papel fundamental desempenhado pelo fenômeno educativo na construção e articulação da hegemonia política das classes trabalhadoras - com o surgimento de uma nova cultura e uma nova concepção de mundo que é gestada por estas classes no interior mesmo da sociedade capitalista".

Para BUENO (1986) "todos os processos educativos, assim como suas respectivas ideologias e meios, têm por base uma determinada pedagogia, isto é, uma concepção de como se consegue que as pessoas aprendam alguma coisa, a partir daí, modifiquem seu comportamento. A pedagogia escolhida (de transmissão, do condicionamento ou da problematização), por sua vez, se fundamenta em uma determinada epistemologia ou teoria do conhecimento".

Quanto à educação em enfermagem, BUENO (1986) afirma que "as influências da pedagogia da transmissão e do conhecimento, de um modo geral, ao nível do social revelam um profissional conformista, com falta de conhecimento da própria realidade, individualista, não participativo, não cooperativo, e que procura manter o 'status quo'. Segundo BORDENAVE, é um profissional que não possue desenvolvimento de consciência crítica da realidade que, portanto, está suscetível a manipulações ideológicas ou tecnológicas".

De acordo com BARROS (1981) "vários objetivos têm sido acrescidos ao substantivo Enfermagem, tais como: Enfermagem de Saúde Pública, Hospitalar, Sanitária, Comunitária e no momento Social. Estas tentativas de colocar roupagens novas no substantivo Enfermagem, talvez reflita o desejo de se reconsiderar este que se encontra desacreditado, desgastado ou mesmo desvalorizado, quando se observa a sua inoperância na solução dos problemas de saúde da sociedade".

CARDOSO DE MELO (1984) define "educação e saúde são práticas sociais... A saúde é uma prática social atravessada pela educação - os indivíduos se preparam para as funções de tratar os males. ...É necessário pensar a educação sanitarizada (educação sanitária) ou localizada no interior da saúde (educação saúde) ou ainda educação para a saúde (como se a saúde pudesse ser um estado que se atingisse depois de educado!). É preciso recuperar a dimensão da Educação e da Saúde/doença e estabelecer as articulações entre esses dois campos e os movimentos (organizados) sociais. E mais - como práticas sociais articuladas com as necessidades e possibilidades das classes populares na formulação de políticas sociais e das formas de or- ganização social que lhes interessam" (BRASIL, 1982 b)

Para PINTO "as diretrizes do Ministério da Saúde referente às ações de saúde junto às populações incluem um processo educativo a ser levado a cabo por métodos participativos. ...Ao analisarmos aqui algumas das características do processo de educação, partimos da admissão de que existem dois saberes: o saber técnico e o saber popular distintos mas não essencialmente opostos, e que a educação, como processo social, exigirá o confronto e a superação destes dois saberes" (BRASIL, 1982b).

O que foi possível notar, através dos vários periódicos analisados, é que há um discurso atual presente na fala dos ideólogos da Enfermagem e do Estado, mas que não se realiza na prática, onde o discurso ainda é predominantemente curativo e visa "educar" o paciente, sem levar em consideração as estruturas sociais onde ele está inserido, e que de paciente (alguém que recebe), deve passar a ser visto e aceito como cliente (alguém que irá trocar alguma coisa).

Não ficou claro nos discursos que serão analisados abaixo, se realmente não há a preocupação com o social, ou se ele é tão relegado pelo enfermeiro e outros profissionais da saúde, que não tem a preocupação de falar sobre ele nos trabalhos publicados.

Para ALMEIDA (1972) "a educação como elemento básico ao trabalho de saúde é bastante reconhecida, aceita e usada por quase todas as pessoas deste setor. A finalidade do processo educativo é conseguir mudança: mudança de informações, atitude ou comportamento e uma de suas etapas é a motivação. ...Portanto, no trabalho educativo da Enfermeira de Saúde Pública, com grupos da comunidade, é necessário sempre verificar quais os incentivos que levam a motivação para assuntos referentes à saúde".

Segundo REZENDE (1984), "o processo educativo é utilizado em saúde, visando mudanças de comportamento. Ensinar há muito deixou de ser transmitir simplesmente informações'

Para NORONHA (1986), " mesmo as pessoas que não têm o domínio do conhecimento formalizado (saber ler e escrever) sabem pensar e decidir e têm, em virtualidade, poder de participar do seu próprio processo de saúde. O trabalho 'com' o cliente é diferente do trabalho 'para' ou 'pelo' cliente, e os profissionais que experimentam esse tipo de abordagem certamente concordarão com essa afirmativa. No entanto, o ato ligado ao ensino-aprendizagem continua mantendo as características formais de cursos de extensão, baseados em demonstrações de procedimentos, geralmente impessoais, abordando um saber não decodificado, como se fora para cumprir uma tarefa de ensino e não, necessariamente discutir experiências e formas de se cuidar (MINAYO, 1986).

De acordo com RAMOS (1976) "a orientação para a saúde consiste no conjunto de ensinamentos que visam à mudança de atitudes, de comportamento, e o de- 
senvolvimento de habilidades úteis à promoção, à manutenção e à recuperação da saúde. "E continua, agora especificamente, referindo-se à clientes diabéticos" há portanto três aspectos a serem considerados na orientação para a saúde: a necessidade que todo indivíduo tem de preservar sua saúde, a valorização dessa necessidade no caso do diabético, pelas implicações da doença, e uma tomada de consciência por parte da Enfermeira, no sentido de assumir o ensino do paciente, como parte integrante de suas funções, inserindo-a na própria assistência de enfermagem".

A função educativa do enfermeiro é definida por SANTOS (1984), "Inclui a orientação ao paciente, família e a grupos da comunidade quanto aos cuidados relativos à prevenção da doença, manutenção e recuperação da saúde. Envolve, ainda, a formação de profissionais e ocupacionais de Enfermagem e atividade docente assistencial, a educação continuada e em serviço de pessoal de enfermagem e o preparo de agentes de saúde da comunidade para a execução de tarefas simples".

No Relatório da Comissão de Declarações e Recomendações do XXXVIII CONGRESSO BRASILEIRO DE ENFERMAGEM, realizado em outubro de 1986 no Rio de Janeiro, temos as seguintes recomendações: 'que os enfermeiros procurem incluir programas sistematizados de ação educativa em suas funções assistenciais e que analisem sua formação profissional sua competência e sua responsabilidade a fim de ef etivar sua contribuição como agente transformador no sistema de saúde. ...que as Escolas de Enfermagem incluam em seus currículos a Educação para a saúde, como disciplina básica para a formação do enfermeiro, como educador em saúde" (RELATÓRIO DA COMISSÃO DE DECLARAÇÕES E RECOMENDAÇÕES, 1986).

Será feita uma pequena revisão bibliográfica para conceituação dos termos formal, não formal e informal.

Para a UNESCO, apud AROUCA (1983), a educação não formal ou extra-escolar significa toda atividade educativa organizada se situando fora do sistema de ensino propriamente dito, seja constituindo uma atividade distinta ou fazendo parte integrante de uma atividade mais ampla, e que se dirige expressamente a um público específico com firalidade específica de aprendizagem. Segundo a mesma autora, ' como se pode perceber através da análise das correntes internacional, americana e européia, a noção de educação permanente, pretende elaborar através de um conjunto sistemático, uma teoria que explique e oriente a ação educativa, no contexto da sociedade contemporânea. O conceito de educação permanente surgiu na Europa, não somente impulsionada pela necessidade da reconstrução pós-guerra, mas também, tentando elaborar um instrumento para superar a limitação dos modelos de educação formal".

"O termo não formal surge no Brasil no III Plano
Setorial de Educação, Cultura e Desporto para 1980/85. ...Em julho de 1963, o MEC através do Ministro Paulo de Tarso confiara a Paulo Freire, a coordenação das atividades no setor de alfabetização de adultos e cultura popular, tomando este Programa as características específicas de seu método" (AROUCA, 1983).

Segundo o Relatório Fauré - citado por FÁVERO (1980) - 'o ṕrincípio da permanência da educação, de acordo com o qual se entende que os indivíduos têm a possibilidade de aprender durante toda a vida, não é apenas a pedra-de-toque na concepção global do desenvolvimento da educação nas sociedades contemporâneas; é também o elemento motor de novas estratégias de educação".

É de COOMBS e AHMED, citados por AROUCA (1983), a definição de educação não formal utilizada atualmente: "qualquer atividade educacional organizada e sistemática que se realiza fora dos quadros do sistema tradicional de ensino, para fornecer determinados tipos selecionados de aprendizagem a subgrupos específicos da população, tanto de adultos como de crianças. Assim definida a educação não formal inclui, por exemplo, ..., diversos programas comunitários, de educação sobre saúde, nutrição, planejamento familiar, cooperativismo, etc".

"Da mesma forma que o relatório Faure, Coombs e Ahmed definem também como informal a educação geralmente desorganizada e freqüentemente assistemática, que envolve todas as pessoas, escolarizadas ou não, durante toda a sua vida e que caracterizam como um processo permanente pelo qual qualquer pessoa adquire e acumula conhecimentos, habilidades, atitudes e perspicácia, através da experiência diária e contato com o meio ambiente em casa; no trabalho e no lazer através do exemplo e das atitudes dos parentes e amigos; por meio de viagens, leitura de jornais e livros; ou ouvindo rádio, vendo filmes e televisão" (FÁVERO, 1980).

As atividades educativas realizadas na saúde com os clientes podem ser consideradas portanto, analisando-se os autores acima, como educação não formal; e a participação dos componentes da equipe multiprofissional quando atuam através dos meios de comunicação ou de outras formas, como educação informal.

\section{COMENTÁRIOS}

Discute-se atualmente a questão da socialização do saber na área de saúde, do fracionamento do poder, na medida em que o cliente deixa de ser paciente e participa com a equipe de saúde, da problemática da saúde. E isto não apenas nos hospitais, ambulatórios, centros de saúde; mas também nas indústrias.

Na revisão bibliográfica feita, não encontramos um discurso compatível com esta tendência, que embora recente aqui, em alguns países, como a Itália, datam da década de sessenta, exceto em algumas Universi- 
dades, em determinados programas.

Em relação à definição dos tipos de educação, se formal, não formal ou informal, a questão deve ficar ao nível de conhecimento, mas não irá influenciar nas atividades realizadas pela equipe multiprofissional que atua na área da saúde.

No discurso dos enfermeiros quando descrevem a atuação da equipe ou deles mesmos, quando analisamos as suas falas, não fica claro se há uma preocupação com o social e se isto não é relevante, e não é citado; ou se os enfermeiros e/ou a equipe ainda têm a visão de saúde-doença como forças opostas.

0 enfermeiro ainda não tem consciência crítica em relação à sociedade e as implicações que ela tem no desenvolvimento de sua atuação junto aos clientes.

\section{CONCLUSÃO}

O levantamento bibliográfico realizado sobre a atuação do enfermeiro no ensino não formal em saúde, em relação à sua prática educativa, permitiu que se chegasse às seguintes conclusões:

A enfermagem como prática social, e o conhecimento à respeito da saúde como um conceito amplo, existe na fala dos "intelectuais orgânicos" da enfermagem.

0 enfermeiro não tem consciência da amplitude de sua atuação profissional, continuando dentro do perfil hospitalar clássico das últimas décadas, utilizando apenas o saber técnico da profissão.

A atuação do enfermeiro em equipe multiprofissional ainda não está largamente difundida e sua atuação se restringe a um profissional da área de saúde.

\section{REFERÊNCIAS BIBLIOGRÁFICAS}

1. ALMEIDA, M.C.P. de \& VINHA V.H.P. A motivação na Educação em Saúde para gestantes. Revista Brasileira de Enfermagem, Rio de Janeiro, 25(5): 93-104, out./dez. 1972.

2. . A prática de Enfermagem como subsídio para a formação do enf ermeiro. In: SEMINÁRIO: A PRÁTICA LE ENFERMAGEM E O CURRÍCULO DA GRADUAÇÃO. Ribeirão Preto, mar. 1985. Anais... Ribeirão Preto, 1985. p. 53-9.

3. AROUCA, L.S. Educação Extra-Escolar e a Realidade Brasileira (Política Governamental para a Formação de Recursos Humanos). São Paulo, PUC, Faculdade de Educação. 1983 , tese dout.

4. BARROS, S.M.P.F. de. Enfermagem Social - seu objeto de trabalho. In: CONGRESSO BRASILEIRO DE ENFERMAGEM, 33, Manaus, 2 a 7 ago. 1981. Anais... Brasília, ABEn, 1981. p. $153-59$

5. BLASS, L.M. de S. et alii. Educação popular: desafios metodológicos. Cadernos do CEDES. São Paulo, 1(1):35-40, 1980.

6. BOLETIM DO CENTRO DE DOCUMENTAÇAO. Educação Popular: bibliografia. Rio de Janeiro, Instituto de Estudos Avançados em Educação. F.G.V., 15(2):1-170, dez. 1986.

7. BRANDÂO, C.R. Da educação fundamental ao fundamental da educação. Cadernos do CEDES, São Paulo, !(1):5-35, 1980.
8. BRASIL. Ministério da Saúde. Ação Participativa: capacitação de Pessoal. Brasília, Centro de Documentação. 1982a.

9. A Ação Participativa: capacitação de pessoal. Brasília, Centro de Documentação. 1982b.

10. BUENO, S.M.V. et alii. Reflexões filosóficas e pedagógicas: contribuição para o estudo da reestruturação dos currículos de enfermagem centrados na proposta de atenção primária à saúde. In: CONGRESSO BRASILEIRO DE ENFERMAGEM, 38, Rio de Janeiro, 20 a 24 out. 1986. xerocópia.

11. CARDOSO DE MELO, J.A. Educação Sanitária: uma visão crítica. Cadernos do CEDES, 2. ed. São Paulo, 4:28-43, 1984.

12. CASTRO, I.B. e. O papel social do Enf ermeiro: Realidade e Perspectivas de Mudança. In: CONGRESSO BRASILEIRO DE ENFERMAGEM, 34, Porto Alegre, 24 a 29 out. 1982. Anais... Brasília, ABEn, 1982. p. 33-52.

13. CONFERÊNCIA NACIONAL DE SAÚDE, 8. Brasília, 1986. Relatório... Ministério da saúde. 17 a 21 mar. 1986. 21p.

14. DOMINGUES, E.F. Trabalho de equipe em Saúde Comunitária - Operacionalização da Enfermagem e suas implicações. Revista da Educação Extra-Escolar, Brasília, 34(3/4):314-26, 1981.

15. FÁVERO, O. (organizador). Tipologia da Educação ExtraEscolar, Brasília, MEC/INEP/FGV/IESAE, 1980.

16. MINAYO, M.C.S. (organizadora). A Saúde em Estado de Choque. Petrópolis, Espaço e Tempo/FASE, 1986.

17. NORONHA, R. Experiência participativa mobilizadora de enfermagem - Condições prévias para o auto-cuidado. Revista Brasileira de Enfermagem, Brasília, 39(1):34-43, jan./mar., 1986.

18. ORGANIZACIÓN MUNDIAL DE LA SALUD. Funcion de los hospitales en los programas de proteción de la salud. Ginebra, 1957. Série de Informes Técnicos, 122.

19. RAMOS, S.M. Necessidade de orientação à saúde do paciente diabético. Revista Brasileira de Enfermagem. Brasília, 29(4):38-41, out./dez. 1976

20. RELATÓRIO DA COMISSÃO DE DECLARAÇÕES E RECOMENDAÇÕES DO XXXVIII CONGRESSO BRASILEIRO DE ENFERMAGEM. Rio de Janeiro. 1986. xerocópia.

21. REZENDE, A.L.M. de. A Enfermagem no Contexto da Saúde. In: CONGRESSO BRASILEIRO DE ENFERMAGEM, 36. Belo Horizonte, 28 jul. a 03 ago. 1984. Anais... Brasília, ABEn, 1984. p. 11-34

22. Saúde: dialética do pensar e do fazer. São Paulo, Cortez, 1986. $159 \mathrm{p}$.

23. RIBEIRO, C. de M. Discurso de abertura do XXXIV Congresso Brasileiro de Enfermagem - Porto Alegre. In: CONGRESSO BRASILEIRO DE ENFERMAGEM, 34, Porto Alegre. 24 a 29out. 1982. Anais... Brasília, 1982. p. 16-8.

24. SANTOS, B.M. de O. et alii, Proposta de um perfil de enfermeiro. Revista Paulista de Enfermagem, São Paulo. 4(4):132-34, out./dez. 1984.

25. SCHMIDT, M.J. Natureza das condições de trabalho da Enfermagem. Revista Paulista de Enfermagem, São Paulo, 4(3): 89-94, jul./set. 1984.

26. SILVA, G.B. de. Aspectos sociais da Enfermagem. Revista da Escola de Enfermagem, USP, São Paulo, 15 (2): 205-09. ago. 1981.

27. SILVA PINTO, S.M.P. \& PAIVA, M.S. Metodologia da Assistência. Uma nova estratégia de educação em saúde. Revista Brasileira de Enfermagem. Porto Alegre. 36(2):177-82, abr./jun. 1983.

28. VIEIRA, T.T. \& SILVA, A.L.C. Recursos humanos na área de enfermagem - Adequação da formação à utilização. In: CONGRESSO BRASILEIRO DE ENFERMAGEM, 34. Porto Alegre, 24 a 28 out. 1982. Anais... Brasília, ABEn, 1982. p. 61-77. 